\title{
The Coalitional Politics of Win-Wins
}

\subsection{Introduction}

Despite the alleged bias towards older people in many political institutions in Europe, this chapter argues that policymakers often do not introduce the most effective policies for supporting healthy ageing. The following pages show that while public spending on older people (e.g. pensions, old age care) remains more extensive and insulated from cuts than other forms of spending, in many (not all) countries policymakers do not introduce policies that would help people age in a healthy way. These latter policies, which include spending on the poorest older people, ensuring access to high quality services and investing across the lifecycle to enable people to enter old age in good health, are often limited.

The chapter then argues that to understand why political institutions simultaneously seem to cater to the needs of older people while often failing to support healthy ageing, we need to conceptualize how the politics of ageing intersect with class, gender and regional dynamics. Building on the framework from the introduction, the chapter turns to the politics of 'win-win' ageing policies. It argues that where political conflict over policies is framed largely intergenerationally, the wellbeing of older people may be preserved in the short run, but less investment in the long-run infrastructure of healthy ageing emerges. By contrast, where cross-class/cross-generational coalitions come together to address gender and class inequities (among the elderly and working age) and develop public services, win-win models can emerge.

\subsubsection{Intra- and Intergenerational Solidarity Across Europe}

One of the core arguments of this book is that policies can powerfully shape the way that individual people, geographic places and larger polities experience demographic changes. Policies will shape whether older people experience more poverty and insecurity in the future than 
today, whether they have access to high quality services and how the costs of ageing are distributed. That policies matter for health ageing is obvious, but what policies matter? When, and where, are they likely to occur? Do democratic processes supply the policies that public health scholars identify as central to health ageing? The following pages argue that healthy ageing requires attention to policies well beyond health itself, something that democratic politics can, but often does not, supply.

First, healthy ageing requires attention to both access to health care and inequalities amongst older people - what we label below intragenerational equality. One of the key claims developed in this book is that older people are not a homogeneous group, but have different needs, capacities and resources. Where policies compensate for these differences by providing access to public services - and, crucially, reduce poverty and inequality amongst the elderly, they also provide the scope for healthy ageing.

Figure 4.1 gives an example of these dynamics. It shows the average share of elderly adult respondents in the EU-SILC survey in 2015 who reported being in 'very good' or 'good' health (as opposed to 'fair', 'bad'
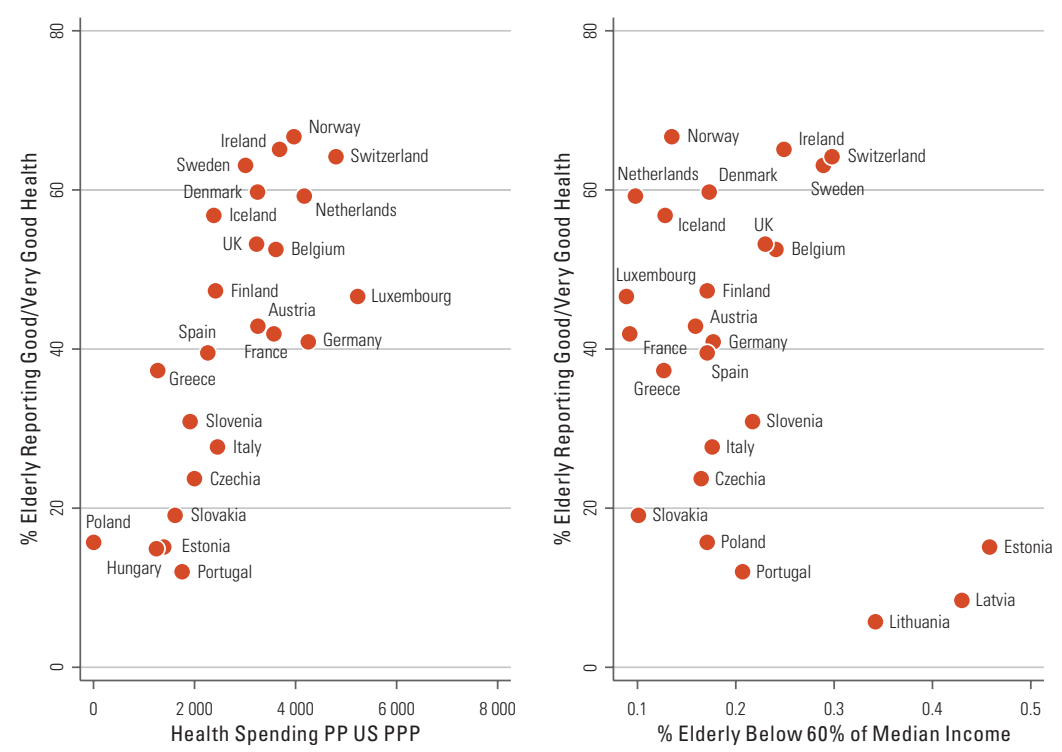

Figure 4.1 Average share of elderly adult respondents.

Source: EU-SILC, 2015 
or 'very bad' health) on the y-axis, plotted against health spending on the $\mathrm{x}$-axis in panel a and elderly poverty rates (measured as 60 per cent of median income) on the $\mathrm{x}$-axis in panel b. Descriptively, Figure 4.1 shows that older people in countries with more health care spending tend to report higher levels of health (the country level correlation in 2015 was $r=.75$ ). However, countries with more health care spending also tend to be wealthier and have larger welfare states, with Lynch (2020) arguing that actual health is a product of the larger approach to tackling income inequality. Panel $\mathrm{b}$ demonstrates this pattern, showing a slightly weaker, but still substantial correlation between post-tax and transfer poverty rates among the elderly and self-reported health.

Second, however, healthy ageing does not start in old age. Attention to the wellbeing of children and working age populations shapes longerrun trajectories. As we argue in Chapters 5 and 6, poverty and lowincome during the working years are linked to lower life expectancy and health risks in old age. Financial stress, lack of access to health care and poor nutrition during childhood and the working years impact both the health risks people face as they enter old age and the resources they have to support themselves. Equally, the skills and activities of the non-elderly population provide key economic and social resources to support those who are already in old age. As Anton Hemerijck (2017) powerfully argues, so called 'social investment' policies that support children, families and skill acquisition through the life-cycle are crucial to funding and sustaining more traditional support policies for older people. In other words, intergenerational equality also is a critical component of healthy ageing.

Figure 4.2, using OECD data averaged over the five-year 2011-2016 period, shows substantial differences in the degree of solidarity within and across generations. On the $\mathrm{x}$-axis, it shows the percentage of older people whose income is less than 60 per cent of the median income. Under 5 per cent of older people are poor based on this definition in the Netherlands, France and Norway (among others), but close to 30 per cent of older people are poor in Estonia. The y-axis demonstrates the share of working age adults who are poor. In a few cases, like Estonia, more than twice as many older people are poor than working age adults, whereas in the Southern European countries, poverty amongst older people is lower than amongst working age adults. Other countries, like Germany and Austria, take a more intermediate position, with roughly similar rates of poverty among older people and working age adults. In 


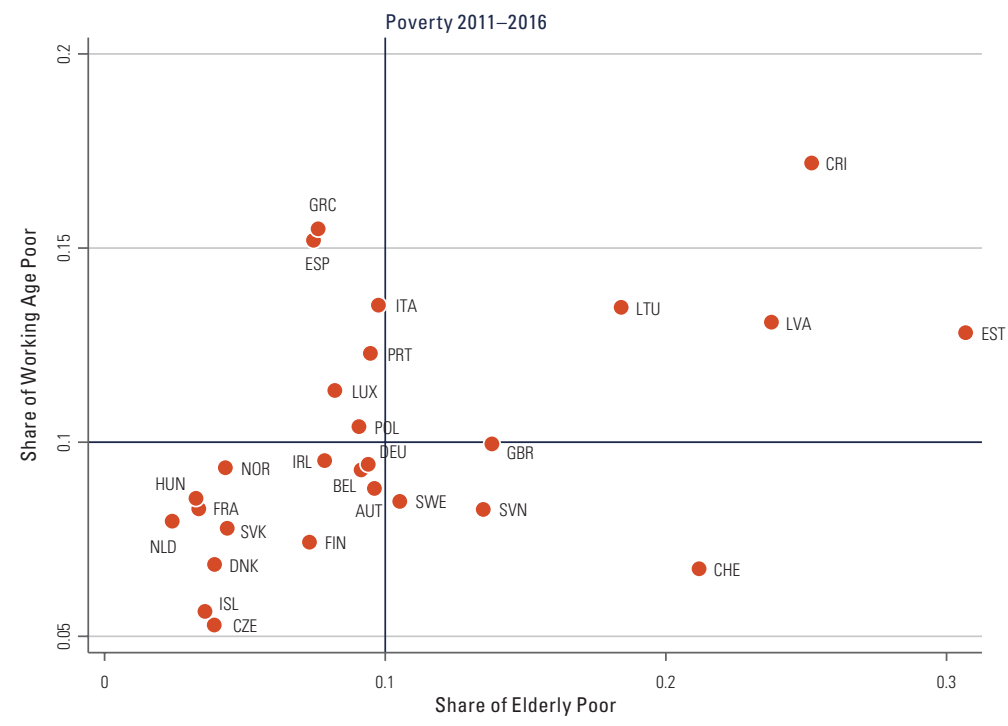

Figure 4.2 Differences in the degree of solidarity within and across generations.

short, there is substantial variation in the degree of intragenerational distribution of resources (i.e. inequality amongst the older and working age cohorts) and the intergenerational distribution of resources (i.e. the relative rates of poverty of older people versus working age adults and children).

Policies shape both intra- and intergenerational solidarity. One of the great public policy successes of the twentieth century was a dramatic reduction of poverty among older people. In the early part of the twentieth century elderly adults, lacking a market income in retirement, were very often poor, relying on their meagre savings or family members to support them, with little additional public or private support. The expansion of public pensions, private occupational pensions and the development of private savings products have allowed people to smooth consumption over their lifetime, dramatically reducing rates of poverty from the early post-war era. However, the extent to which countries adopted these policies varies dramatically. Where welfare policies are more meagre or limited, or ignore the specific risks that some categories of older people face, we may see weaker intragenerational solidarity and more inequality amongst the elderly. By contrast, policies that limit 
such inequalities are generous pensions, health care systems with limited out-of-pocket payments, and accessible and subsidized care services.

Elsewhere, Julia Lynch (2006) demonstrates how different welfare states target non-health spending across age groups, showing differences in the extent to which welfare states devote resources to welfare and target these resources to older people. Where policies are targeted largely at the needs of, or risks faced by, older people, and do not cover those in working age, it can weaken intergenerational solidarity. Conversely, policies that target risks over the life-cycle, including programmes aimed at child poverty (child benefits, housing benefits, in-work benefits or tax credits for families) and childcare, and those for out-of-work adults (both through unemployment and long-run disability), can reduce inequality and poverty among younger people and reduce gaps in both programmatic focus and social outcomes across age groups.

Building on Lynch, we distinguish among four configurations of policy outcomes based on how they redistribute across and within generations. As articulated in earlier chapters, we argue that a win-win configuration pays attention to both inter and intragenerational solidarity. By contrast, a more residual path adopts a more meagre welfare state, accomplishing neither form of solidarity. Age-focused paths are relatively generous for older people, reducing inequality and poverty amongst older people, but do less for working age adults. Finally, some countries offer a limited form of universalism, providing funding across the generations but leaving substantial inequalities in place.

These differences are not merely theoretical, but capture varying choices made across advanced welfare states. Figure 4.3 shows the crosssectional variation in welfare spending, building on a modified version of Lynch's (2006) original measure, comparing non-health spending that primarily goes to older people to spending that primarily goes to

Table 4.1 Paths of solidarity

\begin{tabular}{lll}
\hline & $\begin{array}{l}\text { High Intergenerational } \\
\text { Solidarity }\end{array}$ & $\begin{array}{l}\text { Low Intergenerational } \\
\text { Solidarity }\end{array}$ \\
\hline $\begin{array}{l}\text { High Solidarity Amongst } \\
\text { Elderly }\end{array}$ & Win-Win & Age Focused \\
$\begin{array}{l}\text { Low Solidarity Amongst } \\
\text { Elderly }\end{array}$ & Universal Limited & Residual \\
\hline
\end{tabular}



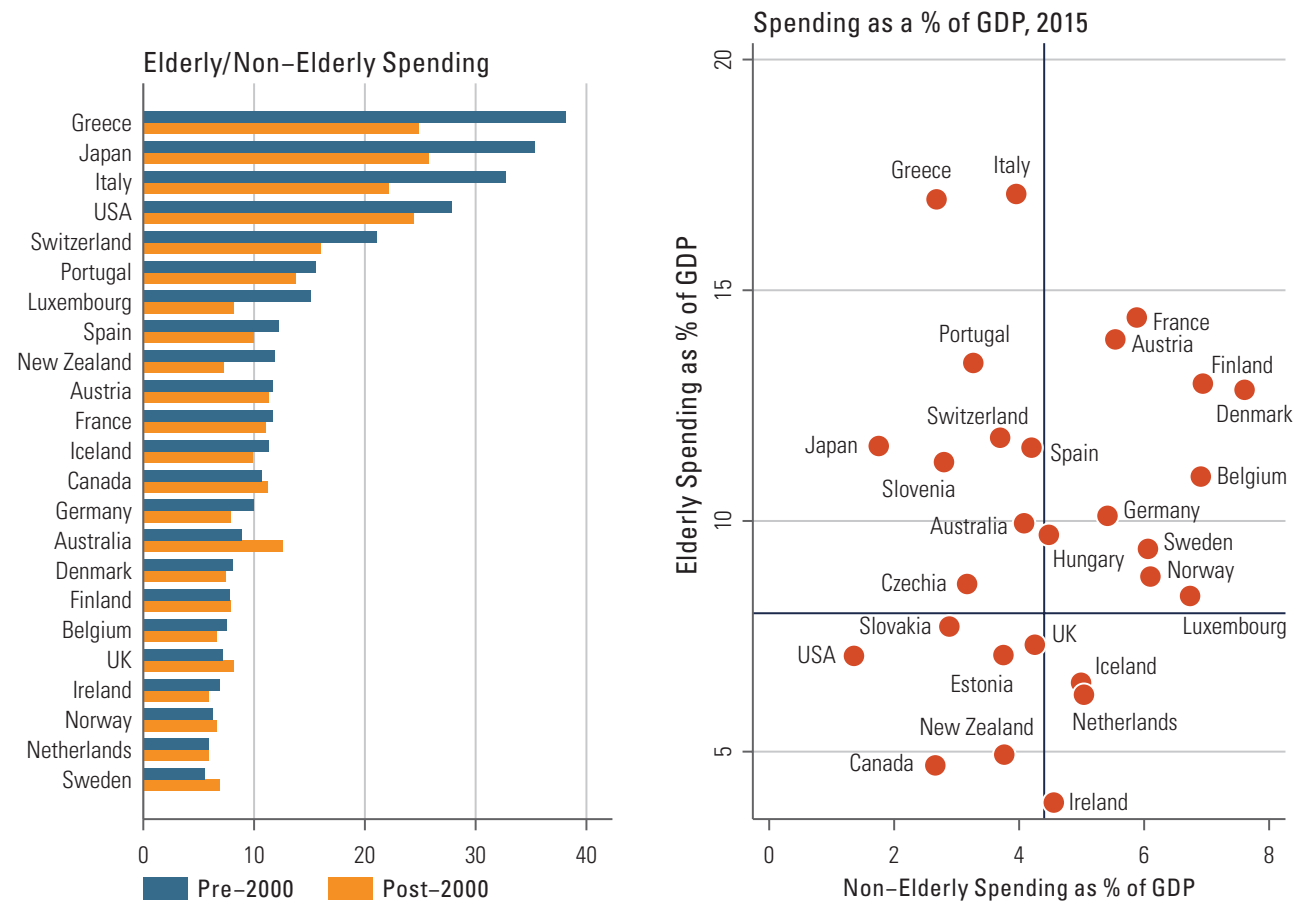

Figure 4.3 Cross-sectional variation in welfare spending.

Source: Building on Lynch, 2006 
non-older people (working age adults and children), relative to their population shares ${ }^{1}$. On the left we see the ratio of the two figures, and on the right the unweighted spending data.

These data show, first, that some countries both distribute resources across the full life-cycle and are relatively generous. In other words, they follow a 'win-win' approach. Historically, the Scandinavian countries developed along these lines, establishing generous pensions and other benefits for the elderly next to working age benefits such as unemployment insurance, later extending extensive benefits to children through the expansion of parental leave policies and other forms of 'social investment' (Morel et al., 2012). The policies that produce this path include child benefits and care services for the very young, housing for young families, training and unemployment benefits for the working age, and large and generous pensions and care services for the elderly, financed by extensive taxes. As shown in Figure 4.3 above, the overall spending generosity in countries like Finland, Denmark, Austria and France matters for social outcomes, limiting inequities both across age groups and within age groups.

A second group of countries have more extensive safety nets for older people than for working age adults or children, redistributing resources to this group. Countries falling closer to the 'age focused' type include Southern European countries like Greece and Italy, as well as Japan. The result is relatively robust protection for older people, but larger gaps between the wellbeing of older people and the working age or child population. In these cases, pensions (and often care) benefits are more extensive than those targeted at young families (housing and childcare services) or working age adults (unemployment benefits). Even where the 'headline' benefits for the working age are quite generous, in practice, in these countries, many workers without permanent jobs are excluded from these benefits, putting them at risk of economic precarity.

\footnotetext{
${ }^{1}$ Spending on older people includes old age pensions and survivors' benefits; non-elderly spending includes spending on incapacity excluding disability pensions, family benefits, unemployment benefits and active labour market benefits. As with Lynch, we exclude housing, other social policy benefits and disability pensions because the age orientation cannot be easily ascertained. One exception is Denmark, where unemployment is counted as private 'other' social policy. Private voluntary spending is not included. All spending is baselined against the share of the elderly in the population. Data are drawn from OECD SOCX, and OECD population data. The inclusion of education spending substantially reduces the gap in spending, but is not strictly social policy. It is therefore not included here.
} 
Third, some countries have more limited welfare states, but a less clear age orientation, or in some cases, a pro-youth structure. The UK forms an example of such a 'universal limited' welfare state, with historically relatively moderate pension benefits and unemployment benefits. In the 2000s, during a period of some welfare expansion, the government uprated both pensions and child and housing benefits, reducing poverty for both groups, but leaving large gaps in coverage among the working age (e.g. limited unemployment benefits, little retraining). In contrast to very meagre systems, there are benefits that moderate income shocks across each stage of the life-cycle, but the smaller size of these benefits leaves the elderly vulnerable to greater poverty.

Finally, in a fourth group of countries, solidarity is low both across and within generations, leaving both older people and the working age community exposed. The Eastern European countries in the bottom left quadrant, like Estonia and Slovakia, as well as the USA and Canada, have lower overall spending on both groups, even as the USA is heavily focused on older people overall. The result is higher rates of poverty, and lower solidarity within and across generations.

In sum, Table 4.1 and Figure 4.3 demonstrate that packages of 'winwin' policies exist - and are associated with more equitable outcomes but they are far from universal. Some countries have developed models of protection that are much more extensively skewed towards older people than other groups, while some provide more meagre benefits overall.

\subsection{Intra- and Intergenerational Solidarity in an Era of Austerity}

The previous section showed that the variation Lynch (2006) identified in the age-orientation of welfare states, combined with broader and well theorized differences in generosity (e.g. Esping-Andersen, 1990), continue to lead to substantial differences in the way policies shape solidarity across and within generations. However, over the last decades the growth of welfare spending has slowed, overall inequality has risen and substantial cuts in some forms of benefits have occurred, while others have been 'recalibrated' to meet new needs (e.g. Hemerijck, 2013; Huber \& Stephens, 2015).

In spite of the promotion of a 'social investment' agenda in the European Union and beyond (Jenson \& Saint-Martin, 2003), there has been no uniform trend towards 'win-win' policies. To return to 
Figure 4.3, we see substantial overtime continuity. There is some move towards more relative spending on younger people in Southern Europe between 2000 and 2010, but spending on older people in these countries is still more extensive by a wide margin than spending on social benefits for the working age population. The financial crisis of 2008 further unsettled some of these gains for younger people.

Indeed, in the face of more recent fiscal pressures, it appears that the benefits for the elderly have been more robust and less likely to see cuts than benefits for working age adults. Work by Mertens (2017) and Streeck and Mertens (2013) finds that investment spending, including investment in the human capital of the young, has been more vulnerable to cuts than spending on the old in times of fiscal austerity. In the UK, for instance, benefits for working age residents and children have fallen faster than those for the elderly in the post-crisis period.

Figure 4.4 shows these patterns descriptively, demonstrating trends in elderly and working age poverty rates from the late 1990s to the early 2010s, using the Fiscal Redistribution Database, which draws on the Luxembourg Income Study (Wang \& Caminada, 2017). Unlike the
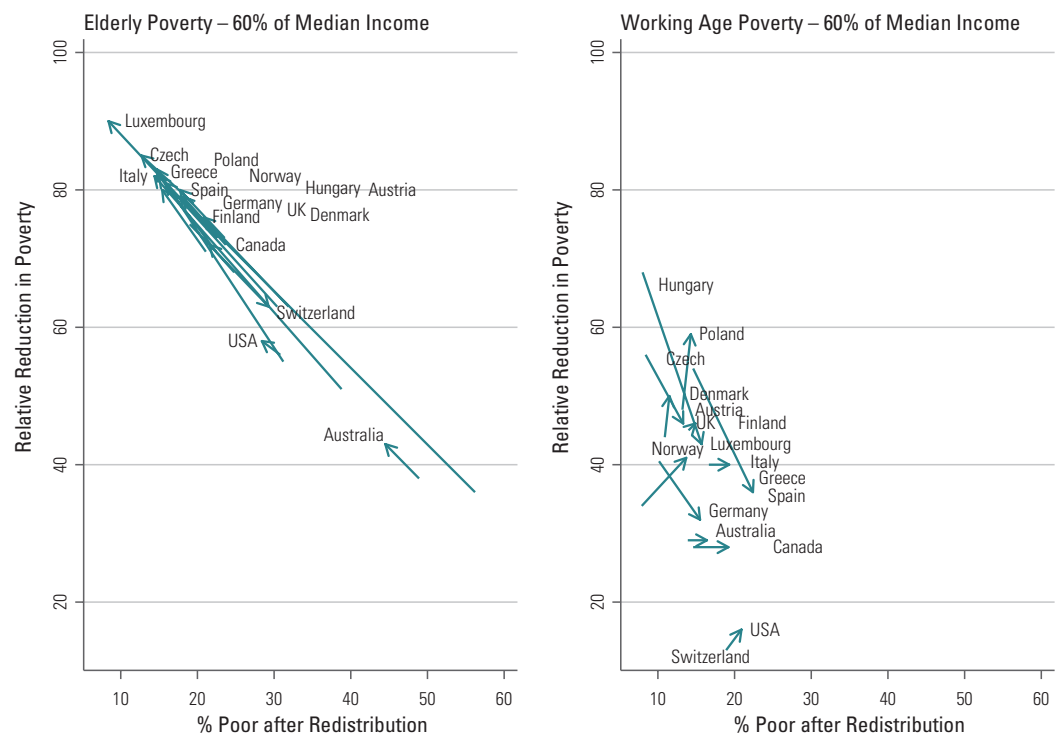

Figure 4.4 Trends in elderly and working age poverty rates from the late 1990 s to the early 2010 s.

Source: Fiscal Redistribution Database 
OECD data above, these data are only available for a smaller range of countries and not for identical periods, but they do exist for a longer time period, allowing an over-time comparison.

Despite some of the limitations of the data, seemingly clear pictures emerge. The x-axis of these graphs, as with Figure 4.2, shows the post-tax and transfer poverty rate for the elderly and working age respectively, with the country labels marking the most recent observation (in the late 2000s or early to mid-2010s). The y-axis shows the relative reduction in poverty from the pre-tax and transfer distribution, in other words, the fiscal effort of the state. What we see is that over time, elderly poverty has fallen in most countries (Switzerland is an exception), while the relative role of redistribution has increased. When we turn to the working age, by contrast, a more diverse set of patterns are at play. In many countries poverty has increased, but in some cases so too has the fiscal effort of the state (e.g. Poland, Norway) while in others the fiscal role of the state has also declined (e.g. Czechia, Germany, Spain).

These trends do not necessarily mean that more age-focused welfare institutions are emerging everywhere. The policy trends are more complex than the outcome data would suggest. First, many cuts to benefits targeted at older people are slow to translate into outcomes, with pension benefit cuts (and expansion) being phased in over many years. Huber and Stephens (2015), in their study of trends in so-called reforms to broad 'social consumption' benefits, argue that a number of cuts to pensions benefits have occurred but that the cuts will become operational in the coming decades. Given uneven private savings and uneven access to private occupational pensions, these shifts portend a long-run reduction in solidarity amongst older people as well as the creation of intergenerational inequities as younger cohorts leave the labour market with less favourable pension arrangements than the older cohorts who were often protected from the immediate consequences of changes in pensions.

Second, for the working age population, in many cases there has been an expansion of transfers to low-income families. A number of countries expanded sometimes quite substantially benefits for families and parental leave through the 1990s and 2000s, including Germany (Morgan, 2013), the UK (Hills et al., 2016) and even parts of Southern Europe. However, at the same time these same countries have cut core income replacement programmes. Rueda (2015) argues, more generally, that existing spending on the working age in areas of unemployment 
and active labour market programmes constitute less of a buffer against insecurity than in the past, particularly as benefits are linked to increasing conditional workfare. Conditionality opens the path for policymakers to depress access to benefits through the creation and manipulation of administrative burdens (Herd \& Moynihan, 2019). The result is substantial shifts in the distributive structure of benefits within the working age populations, not just across generations.

Over time, these differences across age groups have also meant differences across different generations of citizens (Birnbaum et al., 2017). Today's older people, in some countries, have lived most of their lives with relatively generous benefits, whereas others have witnessed substantial growth or cutbacks over the life-cycle. Tomorrow's older people will have experienced more extensive protection through the lifecycle than past generations in some areas (e.g. parental leave, support for dual earner families) and less extensive protection in others (e.g. unemployment benefits), and will enter old age with stronger public pension systems than past cohorts in some countries (e.g. Canada) and weaker ones in others (e.g. Germany).

Despite these varying policy shifts, the broad cross-place and overtime patterns raise an important set of puzzles. Why have countries largely refrained from overt and visible cuts to benefits for older people, but at the same time failed to invest in healthy ageing? Put differently, why are the win-win policies that constitute a key route to healthy ageing relatively limited, even as policymakers have ostensibly looked to protect benefits for older people?

\subsection{The Politics of Healthy Ageing}

The previous section argued that healthy ageing requires thinking about the distribution of resources across the life-cycle and across places, not just focusing on old-age. Systems that seemingly concentrate 'too many' resources on older people, by failing to invest in the capacities and health of younger populations, or 'too few' resources on the older people by failing to stem social exclusion and poverty among older people, may not necessarily be mis-allocating resources across generations, but under-investing in healthy ageing altogether.

Addressing both income risks and the quality of public services over the life-cycle is expensive, and calls for a large and extensive policy apparatus. While the fiscal costs of pursuing win-win policies 
are an obvious and central part of any explanation as to why they are limited across time and place, costs alone are not enough to explain these patterns. As outlined above, in the period of welfare expansion some countries moved to expand benefits for younger and older groups in tandem, whereas others did not. Equally, in the more recent era some countries have trimmed working age benefits more extensively than those for the elderly, and others have not. Moreover, as argued elsewhere in this book, while ageing has created some generic costs pressures, the extent of demographic change does not in itself require a particular adjustment path (or rule out increasing taxes). Collectively, these shifts raise the question of what types of political configurations shape different adjustment paths.

The following sub-sections make two arguments. First, a large body of work in political science argues that the political coalitions that allow age-focused policies to emerge and persist often also undercut coalitions around healthy ageing. We make sense of this seeming disjuncture between the age-bias of policymaking and the bias against healthy ageing by arguing that to understand the politics of healthy ageing, we need to see ageing policy as a form of redistribution with class, regional and gender implications. Attention to age-based cleavages - often expressed via conflict between insiders and outsiders - can work to demobilize attention to class, regional and gender inequalities. It thus makes constructing a distributive 'win-win' coalition more difficult.

Second, and somewhat ironically, the places with the healthiest ageing potential are those that empower broader and more youth-inclusive political coalitions, which in turn have tended to build more inclusive welfare states, institutionalize longer-time horizons and provide a balance of policies that invest in the future and alleviate poverty and insecurity in the present. Where 'win-win coalitions' have emerged in more recent years, they have often done so through cross-class coalitions built around addressing gender (or other forms of) inequality, rather than exclusively addressing older voters.

\subsubsection{Why is the Win-Win So Difficult to Achieve?}

What explains the age focus of many welfare states? A first line of work, pioneered by Lynch (2006), looks to explicitly examine the age orientation of the welfare state as it emerged in the early era of welfare expansion, through the interwar and post-war period. Lynch asks why 
some countries developed welfare programmes largely via benefits targeted to older people, leading to a high degree of redistribution among older people but a lower corresponding level of spending on the working age population, while others expanded benefits more evenly across age groups.

To explain these choices, Lynch turns to the structure of early programmes and the nature of subsequent party competition. She argues that where early reformers introduced more citizenship-based welfare benefits and political parties subsequently competed for new voters on programmatic lines, parties had an incentive to expand programmes to younger people through citizenship-based policies. By contrast, in countries with more particularistic forms of party competition, parties had fewer incentives to expand programmes beyond existing programmatic insiders, maintaining an older age structure in benefits. The Netherlands is a key example of the former structure, and Italy of the latter dynamic, something that continues to show up in the contemporary data outlined by Figure 4.3.

For Lynch, the structure of party competition and welfare state grow together with a reinforcing logic, in some cases encouraging political parties to expand programmes to attract new voters, while in others to maintain them to retain existing voters. The result is substantial crosstime continuity in the age orientation of the welfare state, with early programme choices having a reinforcing effect. In this framing, 'win-win' policies are possible, but they are, in many ways, the historical exception. The growth of programmatic competition in already universalistic systems is a particularly Northern European phenomenon - with more patronage-oriented party systems, or less stable forms of competition, in much of the globe. Crucially, Lynch shows that in these former cases, more inclusive coalitions emerged behind political parties that allowed them to move beyond targeted appeals to existing constituents.

A second line of work turns from the historical development of the welfare state to its more recent developments, asking explicitly how politicians navigate distributional tradeoffs - including intergenerational tradeoffs - in an era of fiscal constraint.

One stream of work suggests that under these constraints, 'win-win' policies may be particularly difficult due to the time horizons of political actors. The payoff - both politically and economically - to investment in healthy ageing may not manifest for a generation, as younger citizens gain skills and older citizens enter old age in better health, but the costs 
of spending are borne in the present. While expanding programmes to the young in the present has immediate political rewards, many of the benefits with regard to long-term health and productivity require the longer-time horizons relative to immediate costs. This inter-temporal gap can be politically difficult to navigate, giving leaders little ability to claim credit in the present, but having to ask voters to pay upfront costs in terms of increased taxes or other forms of cuts in spending.

Alan Jacobs (2011) asks under what conditions policymakers can make choices that 'govern for the long-term'. While long-term expansion and investment are difficult, as Jacobs and others studying pensions show, the long-time horizon policymakers have engaged in both cuts and 'recalibration' to pensions and other systems, often with long-term effects, thus long-term is not impossible but difficult. Jacobs' approach does not necessarily predict age-skewed policy, but does suggest that some aspects of win-win policies can be politically difficult.

Jacobs argues that political systems can give actors incentives to invest in long-term solutions - but only under certain conditions. For Jacobs, longer term policies only emerge when policymakers are simultaneously electorally secure, have clear models about the impact of future policies and inhabit institutions that allow policy reforms. Where politicians are less electorally secure, future costs and benefits to policies more contested, or the institutions of political decision-making limit decisive actions, politicians are less willing and able to make inter-temporal tradeoffs. While Jacobs' argument points in a number of directions for explaining shifts, he too emphasizes that broad coalitions, including interest groups with longer time horizons, are key to explaining when politicians can navigate short-termism.

A third line of work further probes the political alignments around expanding different types of spending in the present. A number of recent studies have looked to theorize expenditure on age groups in terms of an electoral tradeoff between social investment and social consumption (Beramendi et al., 2015; Garritzmann et al., 2018) and the relative preferences for orthodox economic policy in an ageing population (Vlandas, 2017). This work argues that different groups of voters prioritize varying forms of expenditure, largely based on their interests in - or outside - the labour market.

Under this tradeoff framing, differences in prioritization emerge by skill, income and age groups for 'investment' versus 'consumption' policies. Older voters and older working age voters, especially those in 
relatively secure jobs, tend to prioritize existing forms of spending on pensions and unemployment insurance. This group has a strong material interest in income transfers that secure their wellbeing, and sees fewer immediate direct benefits to reforms that expand education and training for younger people. By contrast, educated younger people, and some categories of labour market 'outsiders' - those without permanent or secure employment contracts - prefer spending on investment policies like education and active labour market programmes that promise to expand their opportunities in the labour force.

This approach, then, starts from the premise that win-win configurations are often not possible due to constraints on spending, and frames the choice between types of spending as a distributive struggle across age groups and types of workers. While both insiders and outsiders in an unconstrained setting might prefer both forms of spending, where spending is constrained they prioritize differently. This work builds on an older literature suggesting that so-called labour market insiders (which includes former insiders who are now retired) in Europe are a powerful bulwark against welfare state change, including changes involving investment in more 'youth'-oriented policies (Rueda, 2015).

Where insiders and older voters hold more sway, the age orientation will remain skewed to older voters, but these same voters might prevent straight-out cuts and a reduction in the size of the welfare state. In general, this work suggests that insiders tend to have more structural power than outsiders. Both because of their links to traditional left parties and unions (Thelen, 2014), long-standing mobilization as 'policy takers' (Pierson, 1996) and higher propensity to vote (Goerres, 2007), the policy process is more likely to respond to the demands of these groups. The result then, is a relative under-investment in youth-based policies, and many of the pre-requisites to healthy ageing.

Collectively, this literature suggests that 'win-win' policies are very difficult for three reasons: (a) programmes are highly path dependent because the politics that produce them are further reproduced through them, with loss-averse voters and interest groups mobilizing to protect the status quo; (b) voters and politicians face short time horizons, which may be further shortened under conditions of electoral threat from actors explicitly supporting consumption over investment; and (c) sizeable parts of the voting public prioritize current consumption of passive social benefits, which benefits the current older population, but not necessarily healthy ageing. While all three of the above approaches suggest that age 
matters politically, each also suggests that understanding age requires embedding the politics of ageing in a broader political context that looks at how age intersects with existing welfare structures, the nature of partisan political competition and other forms of mobilized political inequalities. Where existing welfare structures benefit insiders, parties have stable support bases and intergenerational inequalities are pitted against other forms of social and economic inequality, more age-focused institutions are likely to emerge and stay in place.

Building on these claims, the following section shows that where agebased policies are politicized in broader equality-promoting coalitions, particularly those seeking gender equality, win-win policies are possible.

\subsection{Coalitions and Healthy Ageing}

The above section suggested win-win policies are difficult to achieve, but some countries have maintained or moved towards them over time, while others have not. What can we learn from those that have introduced such policies? The following section argues that (a) creating win-win outcomes requires broad social coalitions that combine intra- and intergenerational interests, and (b) this combination often involves incorporating actors that explicitly mobilize both sets of issues. Historically, gender-based advocacy groups have played a crucial role, because of their centrality in politicizing both family and labour market issues - drawing together redistributive and intergenerational claims. To see these dynamics, we turn to several instances of reforms towards more 'win-win' outcomes.

The Scandinavian countries have long stood out as key developers of 'social investment'-style policies, and at the forefront of healthy ageing. Lynch (2006) shows that these welfare states have long had a younger structure. However, the move towards social investment in the Scandinavian countries emerged extensively in the 1970s and 1980s, with expansion of benefits targeted at supporting women's entry into the labour force.

This early expansion of parental leave and childcare services - as well as more extensive home and institutional care for the elderly - built on a larger shift in the underlying political coalitions underpinning not just social policy and the welfare state. Sweden, for instance, had relatively under-developed early childhood programmes in the 1960s and 1970s, compared to other European countries (Morgan, 2002). However, the 
expansion of demand for female workers, combined with new demands from feminist groups, put childcare and parental leave policies on the agenda through the 1970 s.

These demands were, however, not narrowly targeted at the state. Thelen (2014) describes the process of change in these countries (focusing in particular on Denmark) in terms of 'embedded flexibilization'. She argues that as women began to enter the labour force, unions representing the public sector and service workers developed more extensive relationships with the traditionally male-dominated manufacturing sector. As the size of the service sector grew, this relationship meant increasing institutional links in wage bargaining between lower productivity labour-intensive service jobs and blue-collar manufacturing jobs. In other words, unions representing public sector workers, an increasingly female workforce, institutionalized more pay equity in the labour market, creating substantial intragenerational redistribution.

As parties across the political spectrum turned to emphasizing support for female labour force participation and expanded childcare and parental leaves, this also meant more support for intergenerational equity - as the already developed system of pensions was complemented with benefits targeting young parents and children (Gingrich \& Ansell, 2015). The result was a robust expansion of a range of social investment policies, without an initial erosion on benefits for the elderly. Put differently, while insider-outsider divides remain relevant in the Scandinavian labour market and in individual voting behaviour (e.g. Lindvall \& Rueda, 2014), the early development of broader coalitions built around women in the public sector (and private service sector), in both the labour movement and electorally, allowed the emergence of more extensive life-cycle policy.

This scenario has changed somewhat over time. Successive governments in a number of Scandinavian countries have trimmed unemployment and pension benefits; and, for instance, in Sweden, the Conservative-led Reinfeldt government substantially cut taxes. Moreover, the marketization of care services, and the broader shift towards more limited institutional care, has meant some changes in the access of services for the elderly (Gingrich 2011). Nonetheless, there remains a strong focus in these welfare states on benefits and services that promote both inter-generational and intra-generational solidarity.

This emphasis shows itself in the nature of political competition. Figure 4.5 demonstrates the number of mentions of welfare and education 

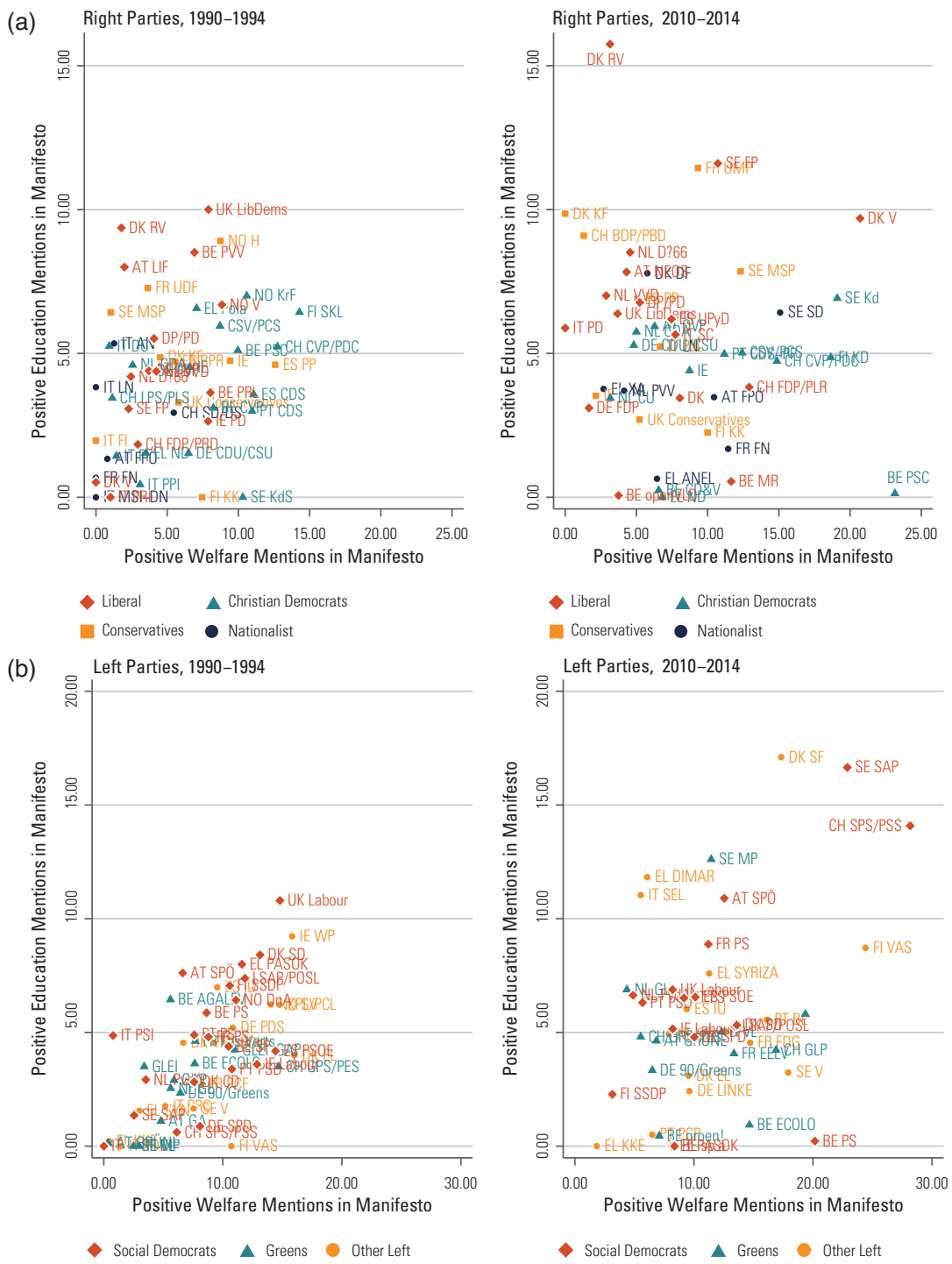

Figure 4.5 The number of mentions of welfare and education in political manifestos, by country.

Source: Volkens et al., 2020 
in political manifestos, by country, as measured by the Comparative Manifestos Project (CMP). The CMP data do not allow us to disaggregate discussions of age groups explicitly, thus we use overall positive mentions of welfare and overall positive mentions of education as a proxy for attention to different age groups. What Figure 4.5 shows is that over time, parties on the Scandinavian left, and to a lesser extent the right as well, have become increasingly positive towards both education and welfare, with parties elsewhere pursuing mixed paths on both dimensions. Even in an era of cutbacks, the attention to wellbeing across the life-cycle in Sweden and Denmark, for instance, is high in comparative terms.

Thelen (2014) contrasts the Scandinavian case to that of continental Europe, particularly Germany, where insider-outsider cleavages continued to dominate through the 1990s and 2000s in both the labour market and electoral politics. Here, the traditional manufacturing unions initially took a less inclusive and coordinating approach to lower wage service workers, allowing increasing wage drift between the manufacturing sector and the low-skilled service sector. Politically, through this time period, as Beramendi and Rueda (2007) argue, the mainstream left also continued to largely represent traditional insiders.

However, even here, where shifts have occurred towards investmenttype policies over the life-cycle, they have built on broader coalitions of younger groups who have often explicitly pushed for greater gender equity and support for family policy. The relatively substantial expansion of childcare in Germany through the 2000s followed in part through the growth of a more electorally mobile female and high skilled electorate (Fleckenstein, 2011; Morgan, 2013). These policies were led in part by the centre-right (the CDU in Germany) and were particularly favourable to higher-skilled women, but nonetheless demonstrate a dynamic of change in which demands for greater gender equity promote a reorientation towards more life-cycle policies. Abou-Chadi and Wagner (2020) find the move towards investment policies can yield electoral gains for the left as well, but only when paired with moderation on 'second dimension' issues like cultural liberalism and gender equity. Particularly in proportional electoral systems, where younger urban voters face less of an aggregation penalty (compared to majoritarian systems, where such voters are 'over concentrated' in cities), voters concerned about gender issues as well as other distributive issues are more able to select parties that put these questions on the agenda. 
Häusermann (2010) shows how possible coalitions of insiders and outsiders, particularly built around gender, can also change the distributive space around benefits in the interest group sphere. Her work examines pension reforms in a number of continental European countries. Contra early work suggesting pensions are 'un-reformable', Häusermann finds that many continental European countries did engage in substantial pension reform, sometimes expanding equity through new pension credits and at other times limiting it. Groups representing women, or broader concerns about gender equity, also played a critical role in this process, albeit to different distributive ends - sometimes facilitating cuts in coalition with centre-right parties and other times expansion.

Why have gender issues been important to new coalitions around the welfare state? Women, like older people, are a heterogeneous group, both in terms of their economic and political behaviours. However, attention to women's historic exclusion from the welfare state, particularly where benefits ran through 'male breadwinners', and the labour market has brought the possibility of new political and interest group coalitions around expansionary life-cycle policies without an immediate erosion of benefits for the elderly.

The tradeoff framework, reviewed above, assumes either a strong budget constraint, no macro-economic effects of investment, and thus a hard tradeoff between expanding investment and maintaining consumption. However, within a family, investment and consumption can be two sides of the same coin (albeit a costly one). Programmes that look to support female participation in the labour force often must bridge the caring needs of both young children and older people. Where this support is done through extensive public policies (rather than more limited forms of tax breaks or credits for caring), it can produce both investment in the skills of the female labour force and consumption for the elderly. The gendered nature of caring (both in the home and the paid labour force) means that attention to wages in the care sector, support and funding for care and family policies can all have the dual effect of expanding benefits for the young while also providing resources to older recipients. Equally, in the area of pensions, in attending to women's more historically uneven participation in the paid labour force, Häusermann points to the uneven access to benefits among the elderly and recognition of career differences over the life-cycle. 
In short, women's historic position in the family has meant that attention to gender equity draws on many intergenerational issues, bringing a more life-course perspective into political discourse. This perspective has sometimes led to win-win policies - with attention to both intergenerational and intragenerational equity - but not always. The Swedish and Danish cases, then, remind us of the key importance of broader coalitions. Where win-win policies have emerged, they have drawn on both the interests of female workers and family policy in conjunction with concerns about equity in the labour market. However, these broad coalitions do not always emerge. Indeed, as Figure 4.6 shows, many moderate left and right parties are much more positive, in relative terms, towards education than towards welfare programmes, and family and education policies are sometimes expanded alongside cuts in other types of spending.

This observation brings us to the last section of the paper, returning to questions of class and other forms of inequality at the heart of ageing policy.

\subsection{New Challenges}

The above section argued that attention to gender equity has, in many European countries, brought more attention to questions of intergenerational solidarity. However, this intergenerational focus is not always accompanied by more attention to intragenerational equity. This chapter concludes with a discussion of two increasingly important issues that highlight the intersection of class and region with intergenerational solidarity. These issues, like the more generic focus on life-course policies discussed above, will be crucial to future healthy ageing.

First, many European countries, including both the older and newer EU member states, have experienced increases in not just income inequality in recent years but also wealth inequality. A large part of this increase has been driven by a boom in asset prices, particularly house prices (Fuller et al., 2020). This growing wealth inequality has clear age-based implications. Older people are more likely to own substantial assets, and in many cases have benefited from appreciation in house prices, but have been harmed by low interest rates on other forms of saving, while younger people are 'locked out' of increasingly expensive housing markets. 

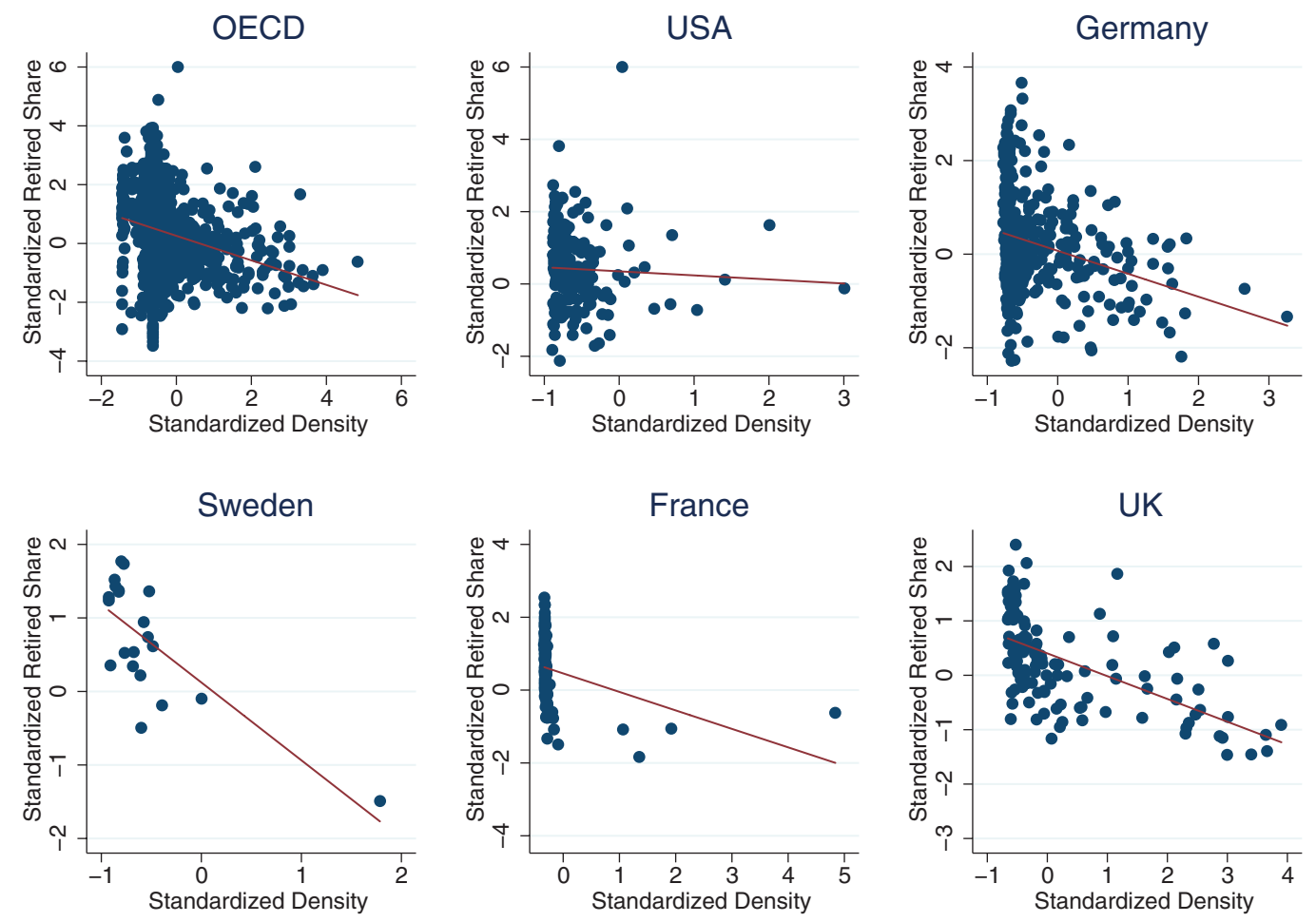

Figure 4.6 Standardized population density versus country-year standardized age structure, NUTS-3 levels or equivalent, 2016. 
Despite the seeming potential for new generational divisions over housing, and wealth more generally, the politics of such shifts have often been 'refamilializing', forcing young people to rely on family wealth - where they can. Bohle and Seabrooke (2020) describe these shifts, in extremis, in terms of 'housing as patrimony'. This reliance highlights one of the key features of the political economy of healthy ageing: what appears as a generational conflict over resources often has a core source in other forms of inequality. Wealth divides that create ostensible intergenerational tension often rest on deeper class divisions. Those who started out wealthier - who had access to assets in the first place - have benefited the most. Bohle and Seabrooke argue that where policymakers in Europe both cut back many social benefits and pursued policies expanding wealth generation, the result has been both rising inequality and reliance on the family.

The politics of family wealth have long been a key issue in Southern Europe, particularly in countries like Italy that combine rigid housing markets and high levels of youth unemployment, reproducing both classand age-based inequalities within and across generations. However, the rapid rise of house prices across the Scandinavian and Anglo countries may portend further shifts along these lines. For instance, Ansell (2014) finds that house price appreciation can push more conservative voters further to the right on social policy and spending, potentially reducing the scope for political coalitions around either form of solidarity. In other words, what appears initially as a potential source of intergenerational conflict rests on a broader set of questions about the future distribution of economic resources both across and within generations - a distribution that will affect the wellbeing of the elderly and of younger generations.

These issues have become particularly pronounced for a second reason: that of growing regional inequality in some cases. While overall regional inequality varies across Europe (both in its level and cross-time trends), house prices have appreciated in particular in Europe's capital regions and densest urban areas, in part due to the rise of the knowledge economy and new economic sectors clustered in urban areas. A growing body of work points to the changing spatial structure of economic growth (Krugman, 1991) and its political consequences (Beramendi, 2012; Iversen \& Soskice, 2019). This rise of more post-industrial economic structures has promoted growth in urban areas, leading to some out-migration of working age adults from declining regions. 
At present, urban-rural gaps in unmet need are not large, but may become larger in the future as declining areas increasingly become home to a larger share of older people. Figure 4.6 shows this connection. Using small regions (NUTS3 in Europe and equivalent regions elsewhere), it shows the country-year standardized population density versus countryyear standardized age structure in 2016. We see that the large dense cities are much younger in many countries, meaning that less dense areas, which are generally experiencing lower levels of overall growth, are often the places where care needs and health needs will be more pronounced. Solidarity among and within generations, then, requires attention not just to income support for each group, but to the quality of services provided in particular areas.

Investing in rural and elderly-heavy areas, however, faces both economic and political limits. As population growth in these areas slows, they may experience a pronounced slowing of private investment (which is already weak by historical standards, relative to the cost of borrowing). This outcome suggests that without some public investment, these regions are likely to face particular long-run disadvantages, disadvantages that could have a strong age component. However, as parties on the left have historically thrived more in cities, and do so even more in the contemporary moment, and parties on the mainstream and more populist right are more sceptical of expanding taxes or public debt, the question of regional cross-age coalitions around public investment is uncertain politically.

Put differently, whereas attention to gender, in politicizing the family, brought intergenerational solidarity onto the agenda, housing and growing urban-rural variation also have inter- and intragenerational components, but the class and regional dynamics around them may split, rather than pull together, coalitions around life-cycle policies and healthy ageing. How future generations will navigate these questions remains to be seen.

\subsection{Conclusion}

When we look across time and place, older people as a whole have been key 'winners' from the expansion of the welfare state. In large part this is a simple cohort effect: those whose formative years were spent in thriving and relatively equal economies move through life with a better situation than those whose formative years were in the 
post-1980s era of increasing inequality, a difference exacerbated by the many countries that have chosen to spend money on avoiding poverty among older people. Behind this broad pattern lie substantial differences in terms of how equal these gains have been amongst the elderly and the degree to which they build on solidarity with other age groups. As such, even where the elderly are major recipients, the policies in place aren't always optimal for healthy ageing - as healthy ageing requires attention to inequality: inequality amongst the elderly and inequality in the population as a whole.

In order to understand why these patterns emerge, we need to examine how politics often does cement intergenerational conflict (through insider-outsider dynamics) and how this conflict, far from preserving the needs of the elderly, often undercuts healthy ageing. When we look at places where a broader life-course perspective emerged, it often drew on cross-generation (and sometimes cross-class) coalitions around gender. Recognizing the need for these coalitions, and paying attention to the changing class and regional issues at the core of healthy ageing, will be crucial going forward. 